\title{
Electrochemical activity of Ni-montmorillonite/Vulcan XC-72R carbon black nano-catalyst for the oxidation of methanol in acidic medium
}

\author{
Mohammad Hossein Sheikh-Mohseni ${ }^{1} \cdot$ Sajjad Sedaghat $^{2}$ (1) $\cdot$ Pirouz Derakhshi $^{3} \cdot$ Aliakbar Safekordi $^{1}$
}

Received: 13 May 2019 / Accepted: 23 July 2019 / Published online: 31 July 2019

(c) The Author(s) 2019

\begin{abstract}
Direct methanol fuel cell is claiming to be the most main power source in future as a clean energy source, for which methanol is used as fuel. In the present study, nickel nanoparticles were synthesized by green route in the presence of montmorillonite (Ni-MMT). Then the electrochemical activity of prepared nanocomposite was investigated in methanol oxidation reaction in acidic medium. In the process of nickel nanoparticle synthesis, the natural substrate montmorillonite was used as capping agent and Allium jesdianum water extract was used as the source of reducing agent for the first time. The Ni-MMT sample was characterized by UV-Vis, XRD, SEM and EDX techniques. Production of nickel nanoparticles in the proposed green method is confirmed by absorption peak of $405 \mathrm{~nm}$ in UV-Vis spectrum. The average particle size of Ni-MMT was determined as $20.80 \mathrm{~nm}$. The oxidation of methanol in acidic medium was studied by cyclic voltammetry using Ni-MMTmodified carbon paste electrode (Ni-MMT/CPE). Methanol was oxidized on the modified electrode surface at $0.3 \mathrm{~V}$. Also, the catalytic current of methanol oxidation was $3 \mathrm{~mA}$ in $\mathrm{H}_{2} \mathrm{SO}_{4}$ electrolyte which is significantly more than unmodified CPE. The concentration of $0.5 \mathrm{M}$ for $\mathrm{H}_{2} \mathrm{SO}_{4}$ was obtained as the optimum electrolyte for the oxidation of methanol. Methanol can be catalyzed in the concentration range of $0.1-0.5 \mathrm{M}$ by the prepared nanostructured catalyst.
\end{abstract}

\section{Graphic abstract}

Ni nanoparticles in montmorillonite (Ni-MMT) which was prepared by Allium jesdianum extract have a good electrocatalytic effect on methanol oxidation.

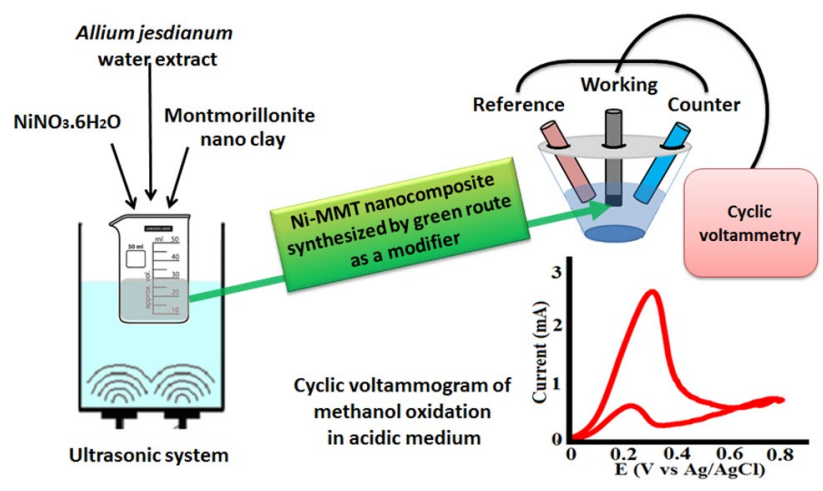

Keywords Methanol oxidation $\cdot$ Metal nanoparticles $\cdot$ Green synthesis $\cdot$ Montmorillonite $\cdot$ Modified electrode

\section{Introduction}

Sajjad Sedaghat

sajjadsedaghat@yahoo.com

Extended author information available on the last page of the article
Fuel cells are electrochemical devices and green power sources with widespread applications in portable and stationary electronic devices. Direct methanol fuel cell (DMFC) is a group of proton-exchange membrane fuel cells (PEM). The 
storage and transport of pure hydrogen gas are difficult compared with methanol as a liquid fuel [1-3]. Low operating temperature, high energy density, easy handling, light weight and availability of the methanol as a fuel are advantages of DMFCs $[4,5]$. However, methanol oxidation at the anode of DMFC has some problems such as slow kinetic and poisoning by the oxidation products. Thus, improvement of the anodic oxidation of methanol has concerned much attention nowadays [6, 7]. Various metal catalysts such as Ag, Pd and Pt have been suggested by researchers for using in DMFCs. However, the high cost and inadequate resources of them limited their applications $[8,9]$.

Nanoparticles due to unique properties and high catalytic activity are used in many scientific fields such as medicine, environment, mechanics, electronics, space industries, chemical industries, catalysis and energy converter science [10]. Nickel-based materials, particularly nickel nanoparticles, have been considered for the oxidation of methanol, because of their electrochemical stability, resistance to poisoning, catalytic performance and low-cost compared with other catalysts. The synthesis and study of nickel nanoparticles are interesting because these nanoparticles exhibit high catalytic activity and high selectivity as a catalyst in different fields $[8,9]$. There are numerous routes to synthesize nickel nanoparticles, such as electrochemical methods [11] and chemical reduction method by chemical [12] or biochemical [13] reductants. In the above-mentioned techniques, chemical reduction by biochemical substances using plant extractions is friendly for environments $[14,15]$.

The synthesis of metal nanoparticles using green chemistry routes has recently been of great interest to scientists because of the using eco-friendly materials such as bacteria, fungi, microbes, biomolecules and plants for the synthesis of nanoparticles. The production of nanoparticles by various medicinal plants has been reported previously. Extract of medicinal plants are rich in phenolic and flavonoid compounds that can act as reducing and capping agents for the synthesis of metal nanoparticles as green route [16, 17].

From the perspective of catalysis, performance of nanoparticles are dependent on particles size, so using suitable support to prevent their aggregation and longer living time in aqueous solution is necessary. Recently, researchers reported the green synthesis of metal nanoparticles supported on the several supports such as eggshell, $\mathrm{Fe}_{3} \mathrm{O}_{4}, \mathrm{TiO}_{2}$, zeolite, graphene oxide, and nanoclay [18-23].

In this work, green leaves and bulb extract of Allium jesdianum (Iranian native medicinal plant) were used for the biosynthesis of nickel nanoparticles. $\mathrm{Ni}(\mathrm{II})$-exchanged montmorillonite (Ni(II)-MMT) used as source of nickel ions and solid support to prevent aggregation of nickel nanoparticles. The morphology of the synthesized nanocomposite and its particle size are determined using SEM and XRD. Energydispersive X-ray analysis, on the other hand, confirms the biosynthesis of nickel nanoparticles. Ni-MMT-synthesized nanocomposite is added as modifier to carbon black (Vulcan XC-72R) for preparing modified carbon paste electrode. Then electrochemical activity of Ni-montmorillonite/Vulcan $\mathrm{XC}-72 \mathrm{R}$ carbon black nano-catalyst was examined towards methanol oxidation reaction in $\mathrm{H}_{2} \mathrm{SO}_{4}$ solution. For this purpose, cyclic voltammetry (CV) technique was employed.

\section{Experimental}

\section{Materials and apparatus}

MMT powder and carbon black (Vulcan XC-72R) were purchased from Fluka and Cabot respectively. Methanol, nickel nitrate, sulfuric acid, paraffin oil and other reagents used in this research were analytical grade from Merck. Doubledistilled water was used for the preparation of all aqueous solutions. Green leaves and bulbs of A. jesdianum were collected in spring 2018 from the southern slopes of the Zagros Mountains (Bell mount in Eghlid city) in Iran. A potentiostat/galvanostat (Autolab, PGSTAT128N, Metrohm) was used for performing the electrochemical tests. The modified carbon paste electrode is applied as the working electrode. $\mathrm{An} \mathrm{Ag} / \mathrm{AgCl}$ (Metrohm) electrode and a platinum rod were used as the reference and auxiliary electrodes, respectively, in a conventional three-electrode cell.

\section{Biosynthesis of Ni-MMT nanocomposite by green route}

To prepare the plant extract, at first, the collected fresh leaves and bulbs of A. jesdianum were washed and then dried in shade under air circulation for a week. After grinding the plant into fine particles, $5 \mathrm{~g}$ of its fine powder was added to $100 \mathrm{ml}$ of double-distilled water and then heated for $20 \mathrm{~min}$ at $65^{\circ} \mathrm{C}$. The mixture was then filtered and centrifuged at $4000 \mathrm{rpm}$ for $10 \mathrm{~min}$. The extract was then stored in a dark bottle at $5{ }^{\circ} \mathrm{C}$ until use. To prepare ion-exchanged form of montmorillonite (Ni(II)-MMT), $1000 \mathrm{mg}$ of MMT was added to $50 \mathrm{ml}$ of $\mathrm{NiNO}_{3} \cdot 6 \mathrm{H}_{2} \mathrm{O}(1 \mathrm{M})$ and stirred for $48 \mathrm{~h}$. Then the resulting mixture was placed in an ultrasonic system and then $4 \mathrm{~mL}$ A. jesdianum water extract was added dropwise for $40 \mathrm{~min}$ at room temperature to convert Ni(II)MMT to Ni-MMT nanocomposite. To remove all nickel-free ions from the mixture, it was centrifuged at $4000 \mathrm{rpm}$ for $10 \mathrm{~min}$, washed by double-distilled water, and repeated.

\section{Preparation of the Ni-MMT/CPE electrodes}

To prepare modified carbon paste, the desired amounts of carbon black (Vulcan XC-72R), paraffin oil (10 wt\% relative to carbon black) and Ni-MMT nanocomposite (20, 30 and 
$40 \mathrm{wt} \%$ relative to total mixture) were thoroughly mixed in an agate mortar. This mixture was put into the polyethylene pipe as keeper and copper wire as electric contact. These prepared electrodes are referred to as Ni-MMT/CPE. Raw carbon paste electrode (CPE) was prepared in the similar way, but without the addition of Ni-MMT. To renew the surface of the electrode, it was polished on the soft paper and then rinsed with double-distilled water [24].

\section{Characterization techniques}

The UV-visible spectra were recorded using a UV BioTEK, UV-visible spectrophotometer. XRD pattern was obtained using diffractometer (XRD, STOE-STADI MP). The FESEM and EDX analyses of nanocomposite were achieved by field emission scanning electron microscopy (MIRA III/FESEM-TESCAN).

\section{Results and discussion}

\section{Characterization of the Ni-MMT nanocomposite}

The absorption spectra at $374-422 \mathrm{~nm}$ range correspond to the nickel nanoparticles as reported in the literature [25]. The absorption spectrum of Ni nanoparticles synthesized by green route in MMT gives a peak centered at $405 \mathrm{~nm}$ that is shown in Fig. 1.

The X-ray diffraction pattern of Ni-MMT was carried out $\left(2 \theta=20^{\circ}-80^{\circ}\right)$ that is shown in Fig. 2. The sharp distinct diffraction peaks at $2 \theta$ angles of $37.32^{\circ}, 44.82^{\circ}, 47.92^{\circ}$ and $75.97^{\circ}$ for green-synthesized Ni nanoparticles related to 111,200 , and 220 crystal planes. This results confirm that nanocomposite includes face-centered cubic (FCC) nickel (JCPDS no. 04-0850) [26, 27]. Other diffraction peaks are related to the structure of MMT [28]. Also, by Debye-Scherrer equation, the average particle size of Ni-MMT nanocomposite was found to be $20 \mathrm{~nm}$.

The FESEM of Ni-MMT nanocomposite is shown in Fig. 3. The FESEM image demonstrates that prepared

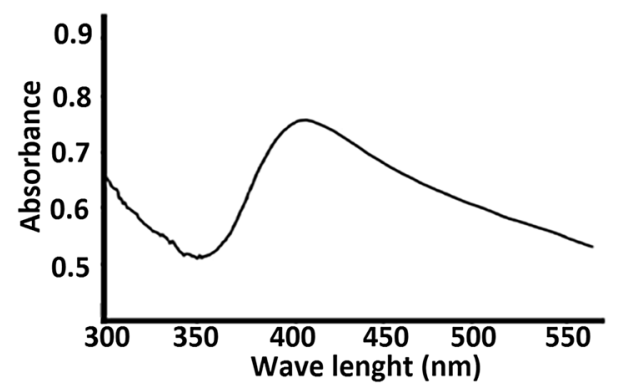

Fig. $1 \mathrm{UV}-$ Vis absorption spectra obtained after the reduction of $\mathrm{Ni}^{2+}$ to Ni nanoparticles in MMT by Allium jesdianum water extract
Ni-MMT was in spherical shape and the particle size was in agreement with XRD analysis. As can be seen in EDX analysis (Fig. 4), the Ni-MMT showed absorption peaks at $0.8,7.5$ and $8.3 \mathrm{keV}$ that are related to $\mathrm{Ni}$ nanoparticles [29]. In addition, the weight percent of the elements that are related to MMT structure and Ni nanoparticles is shown in Table 1. As can be seen, the amount of $\mathrm{Ni}$ atoms is $3.29 \%$ in Ni-MMT, which is close to the expected amount based on the MMT capacitance. This amount of Ni is near to the calculated amount by cationic exchange capacity of MMT, which is $3.5 \% \mathrm{Ni}$.

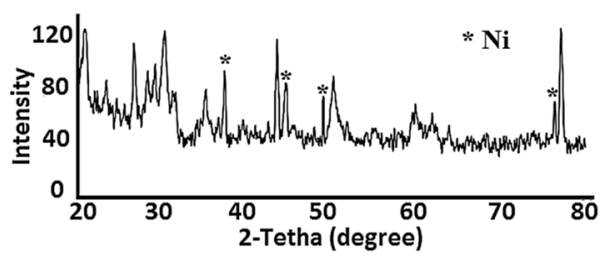

Fig. 2 XRD pattern of Ni nanoparticles in MMT
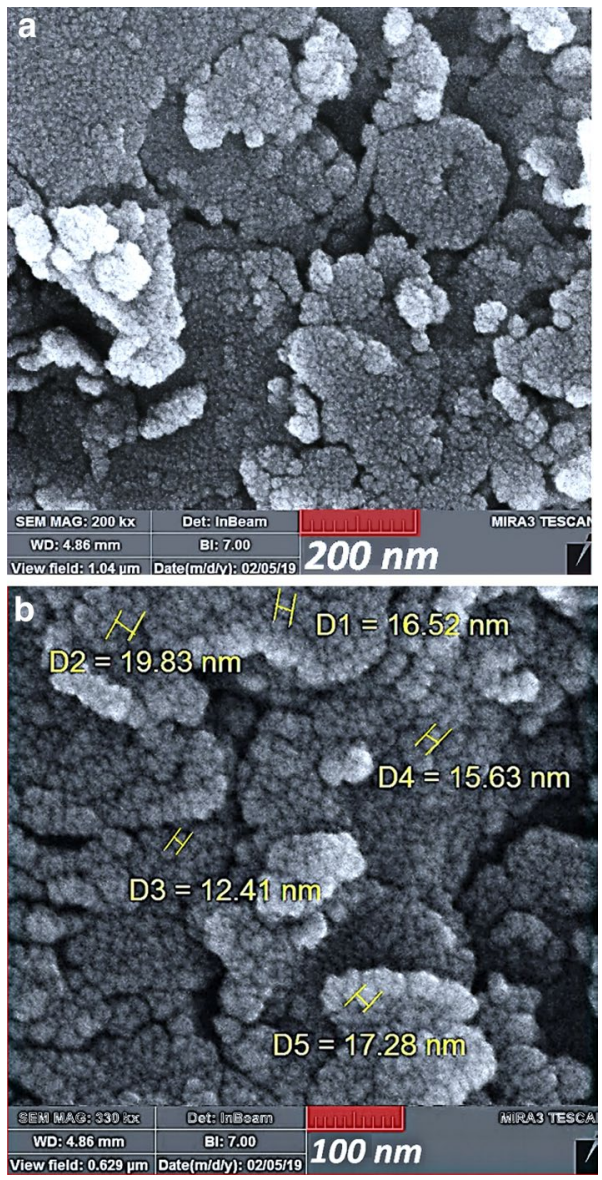

Fig. 3 a FESEM image of the Ni-MMT nanocomposite b as (a) with more magnification 


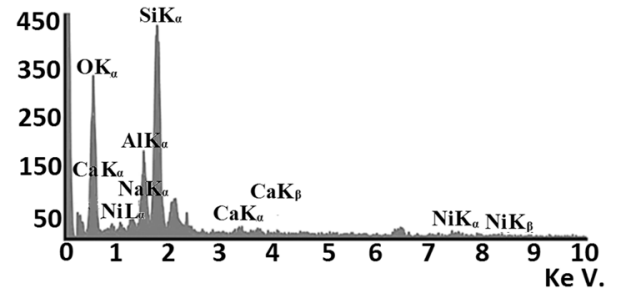

Fig. 4 EDX analysis of the Ni-MMT nanocomposite

Table 1 Weight percent of the elements in Ni-MMT nanocomposite achieved by EDX analysis

\begin{tabular}{lc}
\hline Elements & w/w percent \\
\hline $\mathrm{O}$ & 56.22 \\
$\mathrm{Si}$ & 29.62 \\
$\mathrm{Al}$ & 9.18 \\
$\mathrm{Ni}$ & 3.29 \\
$\mathrm{Na}$ & 0.96 \\
$\mathrm{Ca}$ & 0.73 \\
\hline
\end{tabular}

\section{Methanol oxidation by Ni-MMT/CPE}

The prepared electrodes were used for electrochemical studies. The electro-catalyzing of the methanol oxidation was investigated at the surface of the electrodes. The effect of several parameters such as weight percent of the modifier in the modified electrode, concentration of the electrolyte, concentration of the methanol and scan rate also on methanol oxidation in acidic medium was investigated.

\section{Electro-catalysis of the methanol oxidation in acidic media}

The cyclic voltammograms of Ni-MMT/CPE electrode in the absence [insert (a)] and presence [voltammogram (2)] of methanol in $0.5 \mathrm{M} \mathrm{H}_{2} \mathrm{SO}_{4}$ electrolyte are shown in Fig. 5. The sharp increase of anodic current in voltammogram (2) after the addition of methanol shows the catalytic oxidation of methanol at the surface of the modified electrode according to the literature [30]. The methanol oxidation peak is at potential about $0.23 \mathrm{~V}$ at the surface of Ni-MMT/CPE. Also the anodic current for methanol oxidation is about $0.9 \mathrm{~mA}$ at the modified electrode, whereas the electrochemical response of methanol oxidation is not observable at the unmodified CPE [inset (b) of Fig. 5]. Therefore, the greensynthesized nickel nanoparticles are highly effective for methanol oxidation by Ni-MMT/CPE.

\section{The effect of the modifier percentage on the methanol oxidation}

The cyclic voltammograms of Ni-MMT/CPEs with different weight percent of modifier in $0.1 \mathrm{M}$ methanol and $0.5 \mathrm{M}$

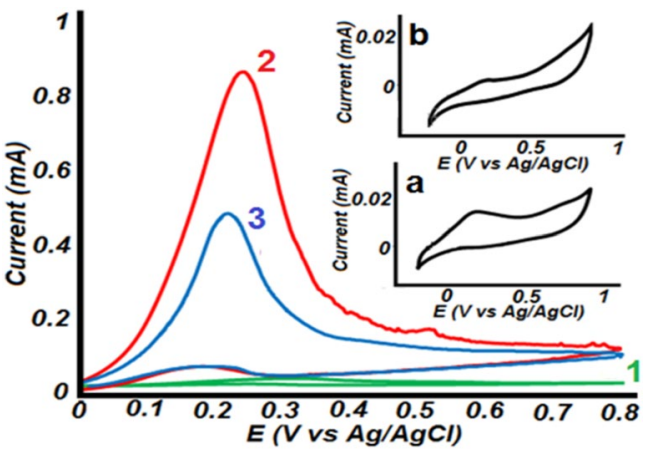

Fig. 5 Cyclic voltammograms of the Ni-MMT/CPE containing (1) 40 , (2) 30 and (3) $20 \%$ of Ni-MMT nanocomposite in $0.1 \mathrm{M}$ methanol and $0.5 \mathrm{M} \mathrm{H}_{2} \mathrm{SO}_{4}$, inset a Ni-MMT/CPE in $0.5 \mathrm{M} \mathrm{H}_{2} \mathrm{SO}_{4}$ in the absence of methanol, inset $\mathbf{b}$ CPE in $0.1 \mathrm{M}$ methanol and $0.5 \mathrm{M}$ $\mathrm{H}_{2} \mathrm{SO}_{4}$; all cyclic voltammograms were recorded at scan rate of $25 \mathrm{mV} \mathrm{s}^{-1}$

$\mathrm{H}_{2} \mathrm{SO}_{4}$ are shown in Fig. 5. As can be seen, the methanol oxidation is changing with variation of Ni-MMT/CPE percentage. The percentage of $30 \mathrm{wt} \%$ of modifier has better performance in methanol oxidation compared to other electrodes (20 and $40 \mathrm{wt} \%$ of modifier). Therefore, the results illustrate that the optimum ratio of the Ni-MMT to the carbon paste was $30 \%$. Lower amounts of the modifier (20 wt $\%$ ) can decrease the effective presence of Ni nanoparticles at the modified electrode surface, while the higher amounts of it (40 wt \%) can decrease the electrochemical signal by increasing the internal resistance of the modified electrode [24].

\section{The effect of electrolyte concentration on methanol oxidation}

The effect of the electrolyte concentration in the range of 0.1-0.5 $\mathrm{M}$ was investigated on the methanol oxidation at $\mathrm{Ni}-\mathrm{MMT} / \mathrm{CPE}$. Figure $6 \mathrm{a}$ shows the obtained results. As can be seen, by increasing the concentration of the $\mathrm{H}_{2} \mathrm{SO}_{4}$, the anodic current of the methanol oxidation was increased at methanol concentration of $0.1 \mathrm{M}$. In addition, by increasing the concentration of the electrolyte, a slightly positive potential shift is observed in Fig. 6a [30]. Therefore, it can be concluded that the $\mathrm{H}_{2} \mathrm{SO}_{4}$ has an essential role in the oxidation of methanol. Also, the optimum concentration of the electrolyte was obtained as $0.5 \mathrm{M}$ with the highest methanol oxidation current. Another object can be observed from Fig. 6a; the anodic current in the reverse scan is remaining constant with variation of the electrolyte concentration [31].

\section{The effect of methanol concentration on methanol oxidation}

The voltammetric response of the Ni-MMT/CPE at different concentrations of methanol $(0.1-0.5 \mathrm{M})$ in $0.5 \mathrm{M} \mathrm{H}_{2} \mathrm{SO}_{4}$ 

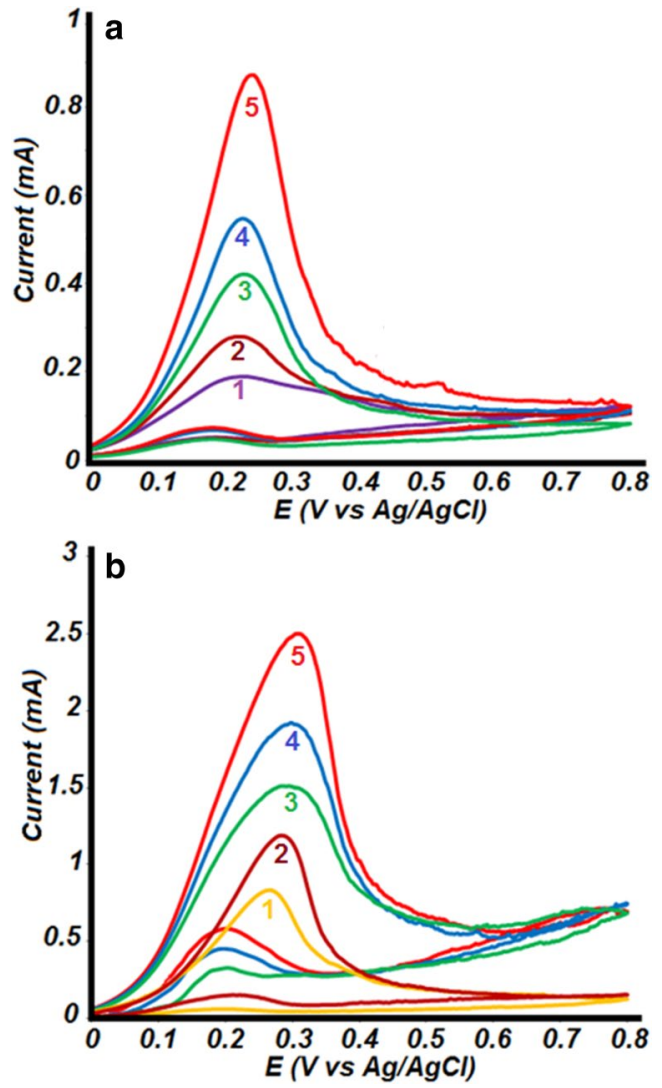

Fig. 6 a Cyclic voltammograms of Ni-MMT/CPE, containing 30\% of Ni-MMT, in $0.1 \mathrm{M}$ methanol and different concentration of $\mathrm{H}_{2} \mathrm{SO}_{4}$ (1-5 correspond to $0.1,0.2,0.3,0.4$ and $0.5 \mathrm{M})$; b cyclic voltammograms of the Ni-MMT/CPE in different concentration of methanol (1-5 correspond to $0.1,0.2,0.3,0.4$ and $0.5 \mathrm{M}$ ) in $0.5 \mathrm{M} \mathrm{H}_{2} \mathrm{SO}_{4}$; all cyclic voltammograms were recorded at scan rate of $25 \mathrm{mV} \mathrm{s}^{-1}$

solution is shown in Fig. 6b. As can be seen, with increasing methanol concentration anodic peak current that related to methanol oxidation is increased [30]. This observation confirms that this peak is for methanol oxidation reaction. In addition, the oxidation of methanol can be catalyzed by the proposed catalyst to a concentration of $0.5 \mathrm{M}$ methanol.

Also, as the results show that the peak current in the negative scan is increased with increasing the methanol concentration (Fig. 6b), but these peaks are not changed by increasing the $\mathrm{H}_{2} \mathrm{SO}_{4}$ concentration (Fig. 6a). Therefore, these peaks can be related to the reduction of methanol oxidation products at the electrode surface $[32,33]$.

\section{The effect of potential scan rate on the methanol oxidation}

The effect of the potential scan rate in the range of 5-45 $\mathrm{mV} \mathrm{s}^{-1}$ on the voltammetric response of Ni-MMT/CPE in $0.5 \mathrm{M}$ methanol and $0.5 \mathrm{M} \mathrm{H}_{2} \mathrm{SO}_{4}$ solution was investigated; Fig. 7 a shows the results. Positive shift of anodic peak with an increase in the scan rate shows the irreversible
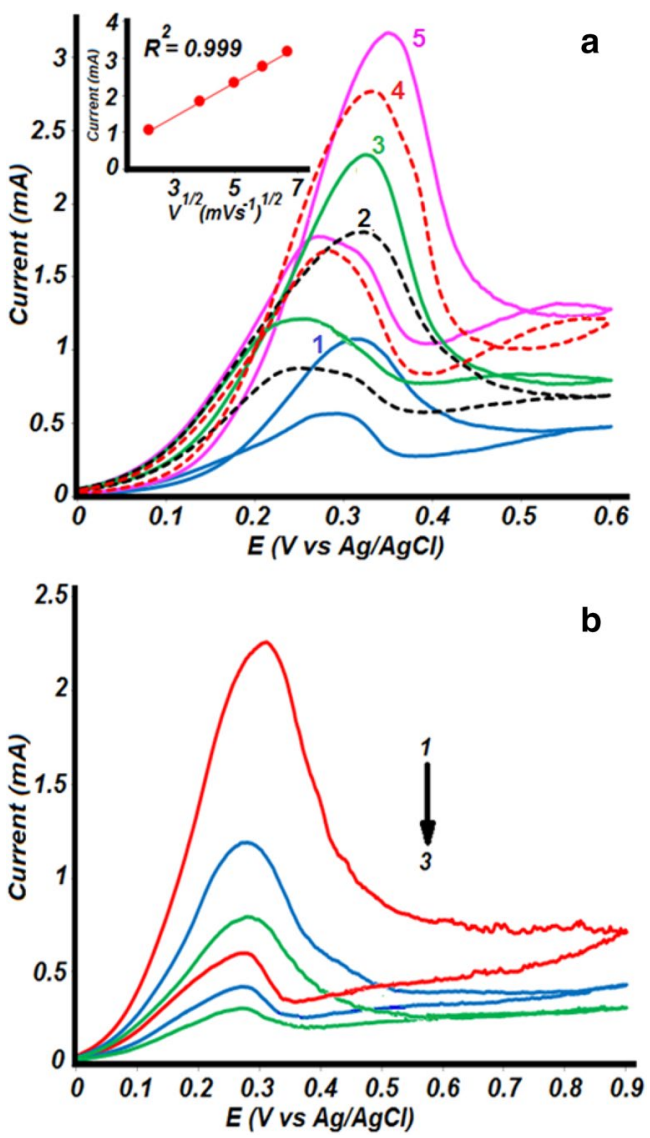

Fig. 7 a Cyclic voltammograms of Ni-MMT/CPE, containing 30\% of Ni-MMT, at different potential scan rates (1-5 correspond to 5, $15,25,35$ and $45 \mathrm{mV} \mathrm{s}^{-1}$ ), insert: variation of peak currents versus square root of potential scan rate; $\mathbf{b}$ successive cyclic voltammograms of the Ni-MMT/CPE during 3 cycles at scan rate of $25 \mathrm{mV} \mathrm{s}^{-1}$; all cyclic voltammograms were recorded in $0.5 \mathrm{M}$ methanol and $0.5 \mathrm{M}$ $\mathrm{H}_{2} \mathrm{SO}_{4}$

electrode process [34]. Also, the potential shift is due to IR drop generated at higher current density values [30]. The linear relationship of methanol oxidation current with the square root of the potential scan rate (inset of Fig. 7a) indicates the methanol oxidation process dependence on the methanol diffusion to the modified electrode surface [35].

\section{The Ni-MMT/CPE ability in re-oxidation of methanol}

The ability of the catalyst in re-oxidation of methanol in successive uses is an important factor. Therefore, this ability was checked by obtaining the cyclic voltammograms in three successive scans (Fig. 7b). A significant decrease of methanol oxidation current during three successive cycles occurred which is shown in Fig. 7a. This is due to electrode surface contamination by oxidation products [32]. This contamination reduces the catalytic performance of the electrode surface in subsequent cycles. Therefore, it is 
Table 2 Comparison of the proposed nano-catalyst with other works

\begin{tabular}{llllll}
\hline Electrode & Modifier & Electrolyte & Oxidation peak potential (V) & Current & References \\
\hline Glassy carbon electrode & $\mathrm{Pt}_{66} \mathrm{Ni}_{27} \mathrm{Ru}_{7}$ & $\mathrm{H}_{2} \mathrm{SO}_{4}$ & 0.6 (vs. SCE) & $4 \mathrm{~mA} \mathrm{~cm}^{-2}$ & {$[36]$} \\
Glassy carbon electrode & $\mathrm{Ni} / \mathrm{SPAni}$ & $\mathrm{H}_{2} \mathrm{SO}_{4}$ & 0.57 (vs. SCE) & $0.3 \mathrm{~mA} \mathrm{~cm}^{-2}$ & {$[31]$} \\
Glassy carbon disk & $\mathrm{Pt} / \mathrm{rGO}-\mathrm{TT}$ & $\mathrm{H}_{2} \mathrm{SO}_{4}$ & 0.9 (vs. RHE) & $4.5 \mathrm{~mA} \mathrm{~cm}^{-2}$ & {$[37]$} \\
Glassy carbon electrode & $\mathrm{Pt}_{2} \mathrm{Au}_{1} \mathrm{Sn}_{1} / \mathrm{CNT}$ & $\mathrm{H}_{2} \mathrm{SO}_{4}$ & 0.7 (vs. Ag/AgCl) & $2.5 \mathrm{~mA}$ & {$[38]$} \\
Glassy carbon disk & $\mathrm{Pt}_{3} \mathrm{Ni}$ nanoframes & $\mathrm{HClO}_{4}$ & 1 (vs. RHE) & $0.75 \mathrm{~mA} \mathrm{~cm}^{-2}$ & {$[39]$} \\
Carbon paste & $\mathrm{Ni}-\mathrm{MMT}$ & $\mathrm{H}_{2} \mathrm{SO}_{4}$ & 0.3 (vs. Ag/AgCl) & $3 \mathrm{~mA}$ & This work \\
\hline
\end{tabular}

necessary to polish the surface of the electrode for revitalizing the catalytic activity of the electrode. The proposed electrode in this work has a renewable surface, which is an important advantage.

For comparing the obtained results with the literature, a comparison table was added. Table 2 summarizes the comparison between the characteristics of the prepared modified carbon paste electrode and some previously modified electrodes [36-39]. As shown, the prepared modified electrode in this research has acceptable performance for methanol oxidation in acidic medium compared to other ones. The oxidation peak of the methanol at the proposed electrode is $0.3 \mathrm{~V}$, which is lower than other electrodes. In addition, the proposed electrode has a renewable surface. Therefore, its surface does not have the serious problem of poisoning.

\section{Conclusion}

Using water extract of A. jesdianum medicinal plant, nickel nanoparticles are successfully synthesized in MMT as a green and cost-effective route. This nanocomposite was confirmed by UV-Vis, XRD and EDX studies and then was used as modifier to make the Ni-MMT/CPE. The prepared nanostructured catalyst was evaluated for methanol oxidation in $\mathrm{H}_{2} \mathrm{SO}_{4}$ solutions by cyclic voltammetry technique. The methanol oxidation was catalyzed by the proposed electrode in acidic conditions, the anodic potential was decreased and its current was increased significantly. The results of the studies showed that the proposed nanocomposite is capable of modifying the carbon paste electrode for methanol oxidation. Therefore, it is possible to use of green chemistry (as an environmentally friendly method) to synthesize metal nanoparticles for the preparation of new catalysts in the oxidation of methanol.

Acknowledgements This work was supported by Science and Research and Shahr-e-Qods Branches of Islamic Azad University of Iran.
Open Access This article is distributed under the terms of the Creative Commons Attribution 4.0 International License (http://creativecommons.org/licenses/by/4.0/), which permits unrestricted use, distribution, and reproduction in any medium, provided you give appropriate credit to the original author(s) and the source, provide a link to the Creative Commons license, and indicate if changes were made.

\section{References}

1. Gonzalez-Espasandin, O., Leob, T.J., Raso, M.A., Navarro, E.: Direct methanol fuel cell (DMFC) and $\mathrm{H} 2$ proton exchange membrane fuel (PEMFC/H2) cell performance under atmospheric flight conditions of unmanned aerial vehicles. Renew. Energ. 130, 762-773 (2019)

2. Mirzaie, R.A., Eshghi, A.: Study of methanol electro-oxidation on $\mathrm{Ni}$ and $\mathrm{Ni}-\mathrm{Pt} /$ carbon paper electrodes for direct methanol fuel cell applications. Surf. Eng. 30, 263-267 (2014)

3. Pieta, I.S., Rathi, A., Pieta, P., Nowakowski, R., Hołdynski, M., Pisarek, M., Kaminska, A., Gawande, M.B., Zboril, R.: Electrocatalytic methanol oxidation over $\mathrm{Cu}, \mathrm{Ni}$ and bimetallic $\mathrm{Cu}-\mathrm{Ni}$ nanoparticles supported on graphitic carbon nitride. Appl. Catal. B 244, 272-283 (2019)

4. Durgadevi, N., Sunitha, M., Asha, S., Guhan, S., Ramachandran, T.: Electro oxidation of methanol on $\mathrm{Ni} / \mathrm{Ni}-\mathrm{Co}$ coated SS mesh electrode. Indian J. Sci. Technol. 9, 1-10 (2016)

5. Xiong, L., Yang, X., Xu, M., Xu, Y., Wu, D.: Pt-Ni alloy nanoparticles supported on multiwalled carbon nanotubes for methanol oxidation in alkaline media. J. Solid State Electrochem. 17, 805-810 (2013)

6. Vecchio, C., Sebastian, D., Alegre, C., Salvatore, A.: Carbonsupported $\mathrm{Pd}$ and $\mathrm{Pd}-\mathrm{Co}$ cathode catalysts for direct methanol fuel cells (DMFCs) operating with high methanol concentration. J. Electroanal. Chem. 808, 464-473 (2018)

7. Wei, X., Yuhong, L., Pan, L.D.: Pt catalysts supported on ligninbased carbon dots for methanol electro-oxidation. Colloids Surf. A. 569, 110-118 (2019)

8. Roh, C.W., Seo, J.Y., Chung, C.H.: Electro-oxidation of methanol on the electrochemically prepared porous nickel hydroxides in alkaline media. Sci. Adv. Mater. 8, 34-40 (2016)

9. Guo, M., Yu, Y., Hu, J.: Nickel nanoparticles for the efficient electrocatalytic oxidation of methanol in an alkaline medium. Electrocatalysis 8, 392-398 (2017)

10. Karakas, K., Celebioglu, A., Celebi, M., Uyar, T., Zahmakiran, M.: Nickel nanoparticles decorated on electrospun polycaprolactone/chitosan nanofibers as flexible, highly active and reusable nanocatalyst in the reduction of nitrophenols under mild conditions. Appl. Catal. B 203, 549-562 (2017) 
11. Ferdowsi, GhS, Seyedsadjadi, S.A., Ghaffarinejad, A.: Ni nanoparticle modified graphite electrode for methanol electrocatalytic oxidation in alkaline media. J Nanostruct. Chem. 5, 17-23 (2015)

12. Chowdhury, S.R., Ghosh, S., Bhattachry, S.K.: Enhanced and synergistic catalysis of one-pot synthesized palladium-nickel alloy nanoparticles for anodic oxidation of methanol in alkali. Electrochim. Acta 250, 124-134 (2017)

13. Ibrahim, F., Aziz, M.H., Fatima, M., Shaheen, F., Ali, S.M., Huang, Q.: In vitro cytotoxicity, MMP and ROS activity of green synthesized nickel oxide nanoparticles using extract of Terminalia chebula against MCF-7 cells. Mater. Lett. 234, 129-133 (2019)

14. Omidi, S., Sedaghat, S., Tahvildari, K., Derakhshi, P., Motiee, F.: Biosynthesis of silver nanocomposite with Tarragon leaf extract and assessment of antibacterial activity. JNCS 8, 171-178 (2018)

15. Sedaghat, S., Omidi, S.: Batch process biosynthesis of silver nanoparticles using Equisetum arvense, leaf extract. Bioinspir. Biomim. Nanobiomater. 1, 2 (2019). https://doi.org/10.1680/jbibn .18 .00045

16. Weng, X., Guo, M., Luo, F., Chen, Z.: One-step green synthesis of bimetallic Fe/Ni nanoparticles by eucalyptus leaf extract: biomolecules identification, characterization and catalytic activity. Chem. Eng. J. 308, 904-911 (2017)

17. Tayade, U.S., Borse, A.U., Meshram, J.S.: First report on Butea monosperma flower extract based nickel nanoparticles green synthesis and characterization. IJSRSET 4, 43-49 (2018)

18. Issaabadi, Z., Nasrollahzadeh, M., Sajadi, M.: Green synthesis of the copper nanoparticles supported on bentonite and investigation of its catalytic activity. J. Clean. Prod. 142, 3584-3591 (2017)

19. Hatamifard, A., Nasrollahzadeh, M., Sajadi, M.: Biosynthesis, characterization and catalytic activity of an $\mathrm{Ag} /$ zeolite nanocomposite for base- and ligand-free oxidative hydroxylation of phenylboronic acid and reduction of a variety of dyes at room temperature. New J. Chem. 40, 2501-2513 (2016)

20. Atarod, M., Nasrollahzadeh, M.: Sajadi, Euphorbia heterophylla leaf extract mediated green synthesis of $\mathrm{Ag} / \mathrm{TiO}_{2}$ nanocomposite and investigation of its excellent catalytic activity for reduction of variety of dyes in water. J. Colloid Interface Sci. 462, 272-279 (2016)

21. Nasrollahzadeh, M., Sajadi, S.M., Hatamifard, A.: Waste chicken eggshell as a natural valuable resource and environmentally benign support for biosynthesis of catalytically active $\mathrm{Cu} / \mathrm{egg}$ shell, $\mathrm{Fe}_{3} \mathrm{O}_{4}$ /eggshell and $\mathrm{Cu} / \mathrm{Fe}_{3} \mathrm{O}_{4}$ /eggshell nanocomposites. Appl. Catal. B Environ. 191, 209-227 (2016)

22. Sedaghat, S.: Green biosynthesis of silver-montmorillonite nanocomposite using water extract of Ziziphora tenuior L. Curr. Nanosci. 12, 79-82 (2016)

23. Sedaghat, S.: Green biosynthesis of silver functionalized multiwalled carbon nanotubes, using Satureja hortensis L. water extract and its bactericidal activity. J. Nanoanal. 4, 59-64 (2017)

24. Sheikh-Mohseni, M.H., Nezamzadeh-Ejhieh, A.: Modification of carbon paste electrode with $\mathrm{Ni}$-clinoptilolite nanoparticles for electrocatalytic oxidation of methanol. Electrochim. Acta 147, 572-581 (2014)

25. Pandian, ChJ, Palanivel, R., Dhananasekaran, S.: Green synthesis of nickel nanoparticles using Ocimum sanctum and their application in dye and pollutant adsorption. Chin. J. Chem. Eng. 23, 1307-1315 (2015)

26. Prasad, Ch., Sreenivasulu, K., Gangadhara, S., Venkateswarlu, P.: Bio inspired green synthesis of $\mathrm{Ni} / \mathrm{Fe}_{3} \mathrm{O}_{4}$ magnetic nanoparticles using Moringa oleifera leaves extract: a magnetically recoverable catalyst for organic dye degradation in aqueous solution. J. Alloys Compd. 700, 252-258 (2017)

27. Singh, H.P., Sharma, S., Sharma, S.K., Sharma, R.K.: Biogenic synthesis of metal nanocatalysts using Mimosa pudica leaves for efficient reduction of aromatic nitrocompounds. RSC Adv. 4, 37816-37825 (2014)

28. Krupskaya, V.V., Zakusin, S.V., Tyupina, E.A., Dorzhieva, O.V., Zhukhlistov, A.P., Belousov, P.E., Timofeeva, M.N.: Experimental study of montmorillonite structure and transformation of its properties under treatment with inorganic acid solutions. Minerals 7, 1-15 (2017)

29. Babu, R.S., Prabhu, P., Narayanan, S.S.: Green synthesized nickel nanoparticles modified electrode in ionic liquid medium and its application towards determination of biomolecules. Talanta 110, 135-143 (2013)

30. Sunitha, M., Durgadevi, N., Sathish, A., Ramachandran, T.: Performance evaluation of nickel as anode catalyst for DMFC in acidic and alkaline medium. J. Fuel Chem. Technol. 46, 592-599 (2018)

31. Das, S., Dutta, K., Kundu, P.P.: Nickel nanocatalysts supported on sulfonated polyaniline: potential toward methanol oxidation and as anode materials for DMFCs. J. Mater. Chem. A 3, 11349-11357 (2015)

32. Richa, B., Jyoti, G., Sunil, S.: High methanol electro-oxidation using $\mathrm{PtCo} /$ reduced graphene oxide ( $\mathrm{rGO}$ ) anode nanocatalysts in direct methanol fuel cell. J. Nanosci. Nanotechnol. 19, 4315-4322 (2019)

33. Ghosh, S., Sahu, R.K., Raj, C.R.: Shape-regulated high yield synthesis of electrocatalytically active branched Pt nanostructures for oxygen reduction and methanol oxidation reactions. J. Mater. Chem. 21, 11973-11980 (2011)

34. Sanli, A.E., Ayta, A.: Electrochemistry of the nickel electrode as a cathode catalyst in the media of acidic peroxide for application of the peroxide fuel cell. J. Electrochem. Soc. 42, 3-22 (2012)

35. Wang, Y., Chen, W., Pan, D., Xu, Q., Ma, J., Zheng, J., Li, R.: Methanol electrooxidation reaction in alkaline medium on glassy carbon electrode modified with ordered mesoporous $\mathrm{Ni} / \mathrm{Al}_{2} \mathrm{O}_{3}$. Int. J. Electrochem. Sci. 12, 2194-2206 (2017)

36. Lu, Y., Wang, W., Chen, X., Zhang, Y., Han, Y., Cheng, Y., Chen, X., Liu, K., Wang, Y., Zhang, Q., Xie, S.: Composition optimized trimetallic PtNiRu dendritic nanostructures as versatile and active electrocatalysts for alcohol oxidation. Nano Res. 12, 651-657 (2019)

37. Arteaga, G., Rivera-Gavidia, L.M., Martinez, S.J., Rizo, R., Pastor, E., Garcia, G.: Methanol oxidation on graphenic-supported platinum catalysts. Surfaces 2, 16-31 (2019)

38. Singh, B., Murad, L., Laffir, F., Dickinson, C., Dempsey, E.: Pt based nanocomposites (mono/bi/tri-metallic) decorated using different carbon supports for methanol electro-oxidation in acidic and basic media. Nanoscale 3, 3334-3349 (2011)

39. Chen, S., Wu, H., Tao, J., Xin, H., Zhu, Y., Chen, J.: Pt-Ni seedcore-frame hierarchical nanostructures and their conversion to nanoframes for enhanced methanol electro-oxidation. Catalysts 39, 1-15 (2019)

Publisher's Note Springer Nature remains neutral with regard to jurisdictional claims in published maps and institutional affiliations. 


\section{Affiliations}

\section{Mohammad Hossein Sheikh-Mohseni ${ }^{1} \cdot$ Sajjad Sedaghat ${ }^{2}{ }^{\circledR} \cdot$ Pirouz Derakhshi $^{3} \cdot$ Aliakbar Safekordi $^{1}$}

1 Department of Chemistry, Science and Research Branch, Islamic Azad University, Tehran, Iran

2 Department of Chemistry, Shahr-e-Qods Branch, Islamic Azad University, Shahr-e-Qods, Iran
3 Department of Chemistry, North Tehran Branch, Islamic Azad University, Tehran, Iran 